\title{
Maksillada Görülen Agresif Fibromatozis, Vaka Sunumu ve Literatür İncelemesi
}

\author{
Aggressive Fibromatosis Involving the Maxilla, Case Report and \\ Review of the Literature
}

\author{
Murat Kaan Erdem, Cengiz Evli, Erdal Erdem, Mehmet Eray Kolsuz \\ Ankara Üniversitesi Diş Hekimliği Fakültesi Ağız, Diş ve Çene Cerrahisi Anabilim Dalı, \\ Ankara, Türkiye
}

\begin{abstract}
Özet: Desmoid tümörler (agresif fibromatozis) lokal agresif büyüme gösteren benign neoplazmlardır ve klinik olarak metastatik potansiyel göstermemektedirler. Baș ve boyun bölgesinde desmoid tümörler çok nadir görülmekte olup, ameliyat sonrası \%46 ile \%62 arasında değişen yüksek nüks eğilimi gösterdikleri tanımlanmıştır. Baş ve boyundaki desmoid tümörlerin klinik özellikleri ve sonuçları hakkında çok az vaka bildirilmiştir. Bu olgu sunumunun amacı günümüze kadar oral bölgede görülen desmoid tümörlerin literatür taraması ve olgu sunumuyla teşhis ve tedavi yöntemlerinin tartışılmasıdır. 17 yaşında erkek hasta kliniğimize üst çene sol arka bölgede 2 aydır iyileşmeyen, yavaş gelişen ağrısız şişlik şikayetiyle başvurmuştur. Alınan anamnezde hastanın herhangi bir sistemik rahatsızlığı olmadığı öğrenilmiştir. Yapılan klinik muayenede maksilla sol premolar molar bölgede (24-26 nolu dişlerin vestibülünde) mukozadan kabarık, sert, üzerinde yer yer ülserasyon gözlenen ağrısız lezyonun varlığı tespit edilmiştir. 5 mm'lik güvenlik sınırlarıyla (fonksiyon koruyucu cerrahi yöntemiyle) yapılan total eksizyon sonrasında lezyon patoloji laboratuvarına gönderilip gelen rapor doğrultusunda Desmoid Tümör (Agresif Fibromatozis) teşhisi konulmuştur. Ameliyata ek radyoterapi uygulanmıştır. Ameliyat sonrası 10 yıllık takipte nüks bulgusu yoktur ve ilgili bölge tamamen iyileşmiştir. Baş ve boyundaki desmoid tümörlerin klinik özellikleri ve tedavi sonuçları hakkında çok az vaka bildirilmiştir. Desmoid tümörlerin tedavisinde birçok seçenek tanımlanmış olup, ortak bir tedavi stratejisine varılamamıştır. Bu tümörlerin tedavilerinde çoğu zaman cerrahi ve onkoterapi kombinasyonları ile başarılı sonuçlar elde edilse de tedavilerinde kesin sonuçlar çıkarmak için daha çok vaka derlemelerinin yapılması gerekmektedir.
\end{abstract}

Anahtar Kelimeler: Desmoid tümör; agresif fibromatozis; maksilla; radyoterapi.

Abstract: Desmoid tumors (aggressive fibromatosis) are nonmalignant neoplasms with locally aggressive growth, but clinically don't display any metastatic potential. In head and neck region desmoids are very rare and described to have a high tendency for recurrance following surgery ranging between $46 \%$ and $62 \%$. A little is reported about clinical features and outcome of desmoid tumors of the head and neck region. The aim of this case report is to review the literature on desmoid tumors in the oral region and to evaluate the diagnosis and treatment methods. A 17-year-old male patient was admitted to our clinic with the complaint of slowly growing, painless mass on the posterior region of the maxilla presetented for 2 months. Medical history was not contrubitory. Clinical examination revealed a firm, regionally ulcerated painless mass on the left premolar and molar (corresponding the vestibule of teeth 24-26) region of the maxilla. After total excision with $5 \mathrm{~mm}$ safety margins (function-protective surgery), the lesion was sent to the pathology laboratory and diagnosed as desmoid tumor (Aggressive Fibromatosis). Adjuvant radiotherapy was applied following the operation. There was no evidence of recurrence in the postoperative 10 year follow-up and healing was uneventful. Few cases have been reported about clinical features and treatment outcomes of desmoid tumors of the head and neck. Many alternatives have been described in the treatment of desmoid tumors and no common treatment strategy has been uniformly agreed upon. Although surgical and oncotherapy combinations are often successful in the treatment of these tumors, more case reviews are needed to obtain definitive results in their treatment.

Keywords: Desmoid tumor; aggressive fibromatosis; maxilla; radiotherapy.

ORCID ID of the authors: M.K.E. 0000-0001-7852-3758, C.E. 0000-0003-4391-2408, M.E.K. 0000-0001-8872-1897, E.E 0000-0001-8131-4519. 


\section{Giriş}

'Desmoid' terimi çizgili kasta ve bazen periosteumda progresif proliferasyon ile meydana gelen tümörün sert, fibröz veya fibroid yapıda oluşu anlamına gelmektedir. Fibromatozisler (Desmoidler), morfolojik sinıflandırmada fibröz konnektif doku lezyonlarından benign bir neoplazm olarak bilinir (1). Yüksek nüks potansiyeline sahip olduklarından agresif fibromatozis olarak da isimlendirilebilmektedir.

Vücutta

görüldükleri bölgelere göre ekstraabdominal, intraabdominal veya abdominal desmoidler olarak adlandırilırlar $(2,3,4)$. Ekstraabdminal desmoidler nadir görülmekte olup, ameliyat sonras $1 \% 20$ ile $\% 77$ arasında değișen nüks eğilimileri ile intraabdominal desmoidlerden daha yüksek rekürrens göstermektedirler (5).

Desmoid tümörler genellikle muskuloapenevrotik sistemdeki dokularda görülmekte olup, baş ve boyun bölgesindekiler genellikle nadir ve çoğunlukla infantlarda ve gençlerde görülüp, başlangıç döneminde hızlı gelişen daha sonrasında ise yavaş seyreden lezyonlardır (4-8). Bu lezyonlar uzak bölgelere metastaz oluşturmasalar da çevre dokulara infiltrasyon gösterebilirler ve destrüksiyon veya kompresyona sebep olabilirler (8). Bu sebeplerle lezyonun cerrahi olarak negatif marjinle eksizyonu zordur ve tedavi sonras $\% 46$ ile $\% 62$ arasında değişen yüksek nüks potansiyeline sahip oldukları bildirilmiştir (5).

Ağızda mandibula çevresi yumuşak dokularda daha sık görülmekte olup bazen ağr1, fonksiyon bozukluğu ve yüzde asimetrilere neden olabilmektedirler. Yumuşak dokunun desmoid tümörleri kemikte görüldüklerinde desmoplastik fibroma olarak da adlandırılırlar. Kemik içinde görülen türleri kemiğin sinırlandırıcı etkisi sebebiyle daha lokalize kalma eğiliminde olsalar da bazen korteksi erode edip çevre dokulara yayılabilmektedirler $(3,4)$.
Histolojik olarak kollajenden zengindirler ve çevre dokuya infiltrasyon gösteren iyi diferansiye fibroblast veya miyofibroblastlardan oluşurlar. Miyofibroblast hücreleri belirgin ise miyofibromatozis olarak da isimlendirilebilmektedirler. Farklı tümör kesitlerinde değişken selülarite görülebilmektedir (10).

Travma, hormonal değișimler, cerrahi skarlar ve yanık fibromatozis oluşma olasılığını arttıran faktörler olsalar da etiyolojileri tam olarak bilinmemektedir. Bazı vakalarda Gardner sendromu ile birlikte görülebilmektedirler (11). Radyografik olarak spesifik olmayan, unilokuler veya multilokuler düzensiz sinırlı görünüm verebilirler. Klinik ve radyolojik görüntüleri ameloblastoma, odontojenik mikzoma, anevrizmal kemik defekti, kondromikzoid fibroma, santral hemanjiyom, eozinofilik granulom ve fibrosarkomlar ile karışabilmektedir $(1,12)$.

$\mathrm{Bu}$ olgu sunumunun amacı oral bölgede görülen desmoid tümörler ile alakalı literatür taraması ve olgu sunumuyla teşhis ve tedavi yöntemlerinin tartışılmasıdır.

\section{Olgu Bildirisi}

17 yaşında erkek hasta kliniğimize üst çene sol arka bölgedeki dişetinde 2 aydır iyileşmeyen şişlik şikayeti ile başvurmuştur. Alınan anamnezde hastanın herhangi bir sistemik rahatsızlığ olmadığı öğrenilmiștir. Yapılan klinik muayenede maksilla sol premolar molar bölgede (24-26 nolu dişlerin vestibülünde) mukozadan kabarık, sert, koyu renkli, üzerinde yer yer ülserasyon gözlenen ağrısız lezyonun varlığı tespit edilmiştir (Resim 1). 


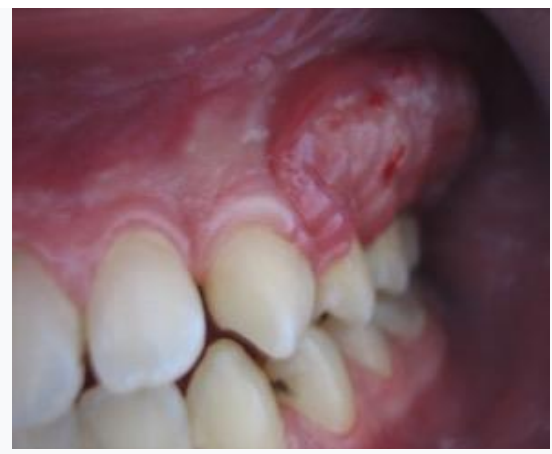

Resim 1. Maksilla sol bölgedeki lezyonun intraoral görüntüsü.

Radyolojik olarak lezyonun kortikal kemiği perfore ettiği görülmekte olup ilgili bölgedeki diş köklerinde rezorpsiyon veya dişlerde migrasyon görülmemektedir (Resim 2). Başlangıçta periferal dev hücreli granülom ön tanısıla insizyonel biyopsi yapılıp biyopsi sonucunda lezyona 'Desmoid Tümör' tanısı konulmuştur. Hasta ve yakınına desmoid tümörün karakteri ve tedavi yöntemleri anlatılıp tümörün radikal eksizyonu ve maksillanın blok rezeksiyonu hakkında bilgi verilmiştir ve hasta kozmetik sebeplerle tümörün radikal eksizyonunu seçmiştir.

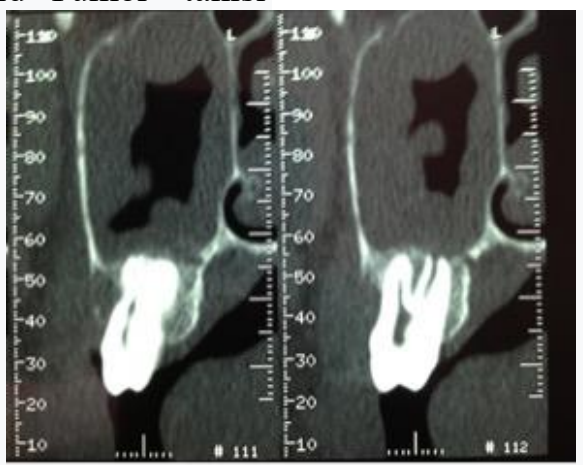

Resim 2. Lezyon bölgesinin BT kesiti, 26 nolu dişin bukkalinde lezyonun kortikal kemiği perfore ettiği görülmektedir.

Genel anestezi altında 5 mm'lik güvenlik sınırlarıyla fonksiyon koruyucu cerrahi yöntemiyle yapılan total eksizyon ve Caldwell-Luc operasyonu sonrasında lezyon patoloji laboratuvarına gönderilmiştir (Resim 3).

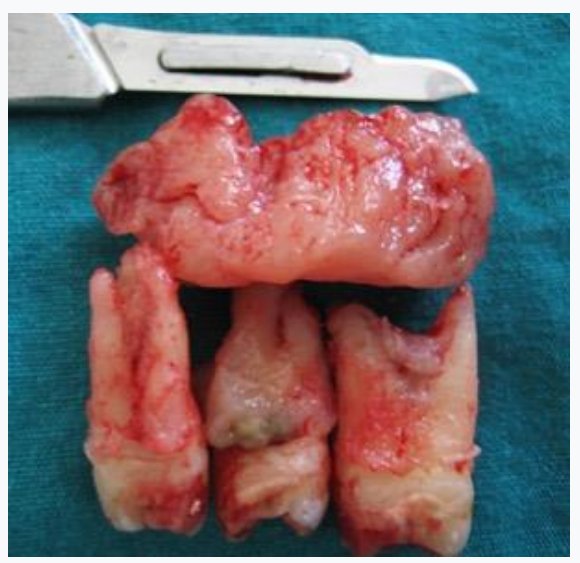

Resim 3. Eksize edilen lezyon ve çekilen dişler. 
Histolojik olarak lezyon, çevresindeki bağ dokusuna ve çizgili kaslara uzanan irregüler nodüler infiltrasyon şeklinde görülmektedir (Resim 4 ve 5). Lezyon birbiri üzerine geçen iğ veya oval şekilli fibroblastik proliferasyon demetleri ile karakterizedir. Hücreler ince tanecikli kromatine sahiptir ve mitoz nadirdir. Hücresel fasiküller arasında ince kolajen lifleri vardır. Lezyon selülerdir ve infiltrasyonun periferik kısmında selülerite artmaktadır. Gelen patoloji raporu doğrultusunda lezyonun Desmoid Tümör (Agresif Fibromatozis) histopatolojik tanisı doğrulanmıştır ve tümör marjinleri negatif olarak bildirilmiştir.

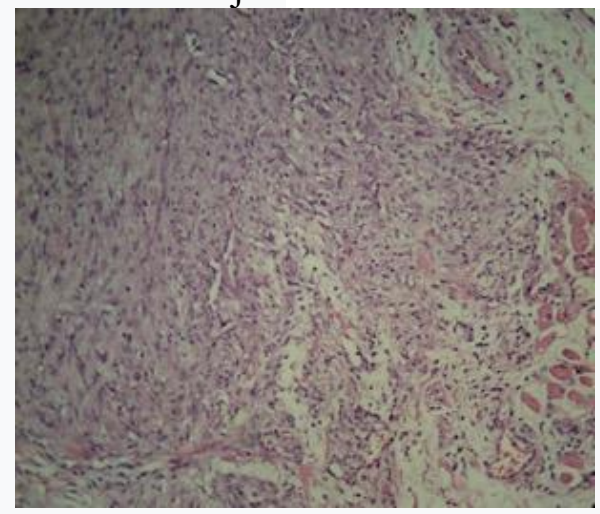

Resim 4. Çizgili kasa uzanan fibromatozun histolojik görünümü (HEX200).

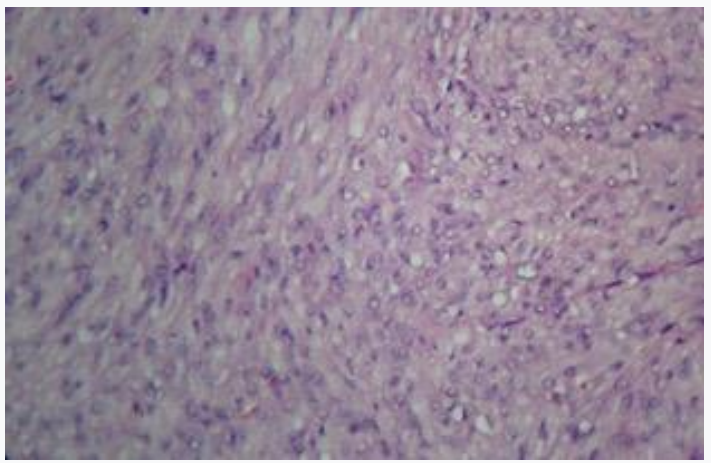

Resim 5. Fibromatozun iğsi şekilde uzanan fibroblast demetlerinin histolojik görünümü (HEX400).

Lokal rekürrensin önlemesi adına ameliyata ek radyoterapi uygulanması amaciyla hasta ilgili birimlere yönlendirilmiștir. Hastanın post-operatif kontrolleri $3,6,9,12$ ve 27 aylarda ve 10. yılda yapılmıştır. Hastanın 10 y1llık takibinde herhangi bir nüks bulgusu yoktur ve iyileşmenin tam olduğu klinik ve radyolojik olarak görülmektedir (Resim $6,7,8)$.

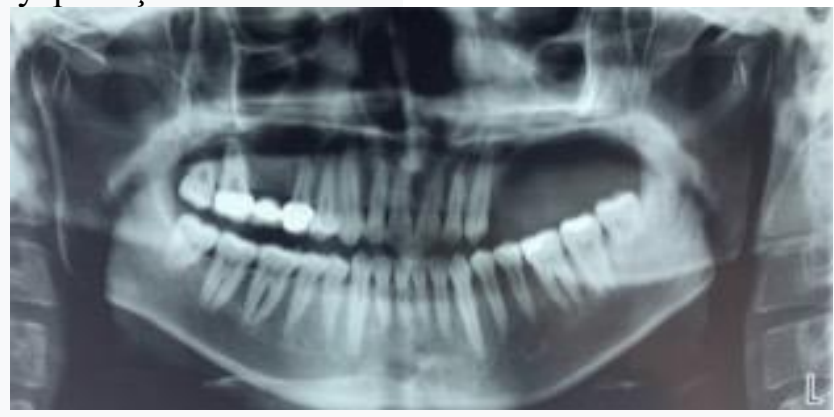

Resim 6. Operasyondan 10 yıl sonraki panoramik radyograf. 


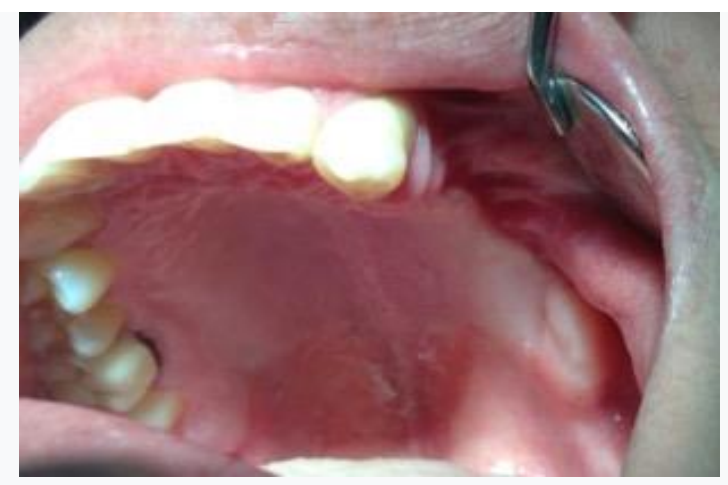

Resim 7. Operasyondan 27 ay sonraki intraoral fotoğraf.

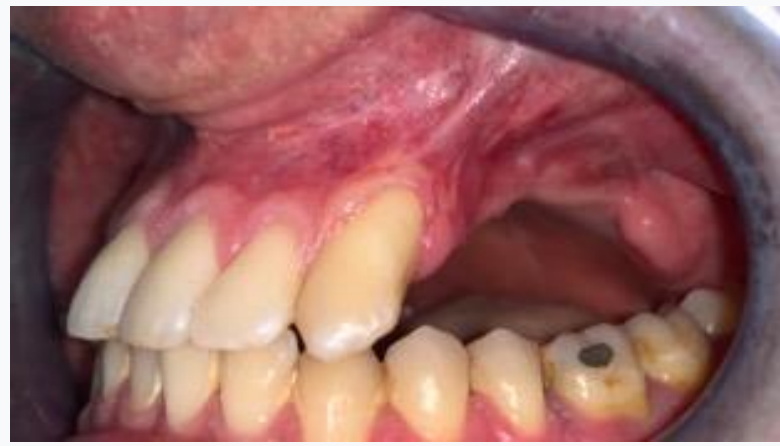

Resim 8. Operasyondan 10 yıl sonraki intraoral fotoğraf.

\section{Tartışma ve Sonuç}

Desmoid tümörler agresif klinik özellik gösteren benign neoplazmlardır ve genç hastalarda tedavi sonrası rekürrens görülme ihtimali yüksektir. Genellikle nüks tedavi sonras1 18 ay içerisinde görülmekte olup 10 y1ldan sonra bile nüks görülen vakalar bildirilmiştir (13). Tümörün infiltrasyon gösteren yapısı ve nüks etme meyili sebebiyle tedavi konusunda farklı görüşler mevcuttur. Bazı yazarlar desmoid tümör tedavilerinde rekürrensin önlenmesi amaciyla blok rezeksiyon önerseler de büyük bir çoğunluk bu tümörlerin benign olduklarını ve majör yapıların sakrifiye edilmesinin gerekli olmadığını, bu yüzden de fonksiyon koruyucu cerrahi yöntemlerle ekstra güvenlik sınırıyla rezeke edilmeleri gerektiğini öne sürmüşlerdir $(5,6,7)$.

Tümör rezeksiyonu sonrasında ciddi morbidite gelişeceği düşünülüyorsa, tümör rezeke edildikten sonra nüks görüldüyse veya rezeke edilen dokuda pozitif marjin varsa adjuvant radyoterapi önerilmektedir $(5,7,14$ 17). Ortalama dozu 50 Gy'lik radyasyon tedavisinin lezyonda lokal kontrolü sağladığ 1 bildirilmiştir $(7,18,19)$. Nuyttens ve ark. (20) 22 makaleyi karşılaştırdıkları derlemelerinde radyoterapi veya cerrahiye ek radyoterapi uygulanan hastalarda sadece cerrahi yapilan hastalara göre çok daha anlamlı lokal kontrol sağlandığını belirtmişlerdir (20). Hoos ve ark. (5) desmoid tümörlerin baş ve boyun bölgesinde rekürrens oranlarının \%46 ile $\% 62$ arasında değiştiğini bildirmiş ve tedavilerinde cerrahide negatif marjine ek radyoterapi uygulandığında üstün sonuçlar elde edilebileceğini söylemişlerdir.

Radyoterapi uygulanmadan önce; önemli anatomik yapıların bulunduğu baş ve boyun bölgesinde radyasyon ile ilişkili morbidite, parestezi, fibrosis, ödem, kırık ve çocuklarda büyüme ve gelişimin etkilenmesi gibi önemli komplikasyonlar olabileceği unutulmamalıdır (20).

Antihormonal ilaçlar (Tamoxifen) ve non steroid anti inflamatuar ilaçların kullanımının da desmoid tümör tedavilerinde faydalı olabileceği düşünülmektedir (7). Başka bir tedaviye ek veya tek olarak kemoterapi de 
tedavi seçenekleri arasındadır (1). Tullio ve ark. (21) kemoterapi ile lezyonun küçüldüğünü bildirmiş, sonrasında tümörü rezeke edip başarılı sonuçlar elde etmişlerdir.

Kasper ve arkadaşlarından oluşan Desmoid Çalışma Grubu, 2017 yılında yayınladıkları makalelerinde desmoid tümör tedavilerinde izledikleri standart protokolü açıklamışlardır. Tümör boyutunun çok büyük olmadığı veya hayati risk olmadığı durumlarda lezyonların 1-2 yıl süren takipte küçüldüklerini bildirmişlerdir. Antihormonal ilaçlar (tamoxifen) tek veya non steroid anti inflamatuar ilaçlar ile kombine tedavilerinde sinırlı toksisiteleri sebebiyle kullanılabilmekte olsalar da tedaviye yanıt çok az görülmektedir. Agresif büyüme, antihormonal ilaçlarla tedavi olmaması veya hayati tehlike olduğu durumlarda düşük doz kemoterapi (metotireksat) uygulanabilmektedir. Tercihen 3 ayda 1 olacak şekilde MR ile ilk 1-2 y1l süreyle tümör takip edildikten sonra lezyonda büyüme görülüyorsa tümör tedavisinde medikal tedavi ve radyoterapi veya medikal tedavi, cerrahi ve radyoterapi kombinasyonu uygulanabilir veya medikal tedavi uygulanmaksızın sadece radyoterapi veya

\section{KAYNAKLAR}

1. Seper L, Bürger H, Vormoor J, et al. Agressive fibromatosis involving the mandible-case report and review of the literature. Oral Surg Oral Med Oral Pathol Oral Radiol Endod, 2005;99:30-38.

2. Kruse AL, Luebbers HT, Gratz KW, et al. Aggressive fibromatosis of the head and neck: a new classification based on a literature review. Oral Maxillofac Surg. 2010;14:227-232.

3. Said-Al-Naief N, Fernandes R, Louis P, et al. Desmoplastic fibroma of the jaws. Oral Surg Oral Med Oral Pathol 2006;101:82-94.

4. Günhan Ö. (2015) Oral ve maksillofasiyal patoloji, Ankara: Quintessence Publishing, p. 257259.

5. Hoos A, Lewis JJ, Urist MJ, et al. Desmoid tumors of the head and neck - a clinical study of a rare entity. Head \&Neck 2000;22:814-21

6. Abdelkader M, Riad M, Williams A. Aggressive fibromatosis of the head and neck (desmoid tumours) The Journal of Laryngology \& Otology 2001;115:772-6

7. Suresh CS, Ali AA. Desmoid tumor of the tongue Med Oral Patol Oral Cir Bucal. 2008;13:E761-4 cerrahiyle birlikte radyoterapi uygulanabilmektedir. Kasper ve ark. (22) bu makalelerinde adjuvant radyoterapinin rekürrens riskini azalttığını bildirmişlerdir.

Desmoid tümörler benign neoplazmlar olsalar da tedavi sonrası yüksek nüks potansiyeline sahiptirler. Genellikle nüks tedavi sonrası ilk 18 ay içerisinde görülse de 10 y1l sonrasında bile nüks görülen vakalar bildirilmiştir. Tümörün boyutu, lokalizasyonu, hastanın yaş ve beklentileri tedavide dikkat edilmesi gereken faktörlerdir. Bu olgunun tedavisinde total eksizyon ve fonksiyon koruyucu cerrahi tercih edilmiş olup negatif marjine ek nüksün önlenmesi amaciyla adjuvant radyoterapi uygulanmıştır. Bu tedavi yönteminin faydalı olup olmadığ halen radyasyonla ilişkili morbidite açısından tartışmalıdır ancak 10 y1llk takip sonucunda hastada herhangi bir nüks bulgusu veya morbidite görülmemektedir. Desmoid tümörlerin tedavilerinde birçok tedavi yöntemi tanımlanmış olsa da tedavi stratejisinde ortak bir karar alınamamıştır. Bu sebeple desmoid tümörlerin yönetimi hakkında kesin sonuçlar çıkarmak için başka vakaların derlenmesi gerekmektedir.

8. Richter M, Chausse JM. Infrequent tumors of the mandible. removal and reconstruction. Acta Stomatol Belg. 1989;86:265-74.

9. Angiero F, Benedicenti S, Stefani M. Fibromatosis of the head and neck: morphological, immunohistochemical and clinical features. Anticancer Research, 2008;28:1725-32.

10. MacKenzie DH. The fibromatoses: a clinicopathological concept. British Medical Journal, 1972;4:277-81.

11. Pinheiro LV, Fagundes JJ, Coy CS, et al. Multiple desmoid tumors in a patient with Gardner's syndrome. report of a case. Int J Surg Case Rep. 2014;5:370-4.

12. Hu T, Jing G, Lv K. Aggressive fibromatosis in the maxilla. $\mathrm{Br} J$ Oral Maxillofac Surg. 2009;47:129-31.

13. Ballo MT, Zagars GK, Pollack A, et al. Desmoid tumor: prognostic factors and outcome after surgery, radiation therapy, or combined surgery and radiation therapy. J Clin Oncol. 1999;17:158167.

14. Watzinger F, Turhani D, Wutzl A, et al. Aggressive fibromatosis of the mandible: a case 
report. Int J. Oral Maxillofac. Surg. 2005; 34:2113.

15. Bataini JP, Belloir C, Mazabraud A, et al. Desmoid tumors in adults:the role of radiotheraphy in their management. The American Journal of Surgery 1988;155:754-60

16. Suit HD. Radiation dose and response of desmoids tumors. Int J Radiat Oncol Biol Phys. 1990;19:3740

17. Zlotecki RA, Scarborough MT, Morris CG, et al. External beam radiotheraphy for primary and adjuvant management of aggressive fibromatosis. Int J Radiat Oncol Biol Phys. 2002;54:177-81.

18. Sherman NE, Romsdahl M, Evans H, et al. Desmoid tumors: a 20-year radiotheraphy experience. Int $j$ Radiat Oncol Biol Phys. 1990;19:37-40

19. Mc Collough WM, Parson JT, Van der Griend R, et al. Radiation therapy for aggressive fibromatosis. J Bone Joint Surg Am. 1991;73:71725 .

20. Nuyttens JJ, Rust PF, Thomas CR Jr, Turrisi AT III. Surgery versus radiation therapy for patients with aggressive fibromatosis or desmoid tumors: a comparative review of 22 articles. Cancer. 2000;88:1517-23.

21. Tullio A, Sesenna E, Raffaini M. Aggressive juvenile fibromatosis. Minerva Stomatol. 1990;39:7777-81

22. Kasper B, Baumgarten C, Garcia J, et al. An update on the management of sporadic desmoidtype fibromatosis: a European Consensus Initiative between Sarcoma Patients EuroNet (SPAEN) and European Organization for Research and Treatment of Cancer (EORTC)/Soft Tissue and Bone Sarcoma Group (STBSG). Ann Oncol. 2017;28:2399-408. 